\title{
COMMUNICATION, COORDINATION, AND NETWORKS
}

\author{
Syngjoo Choi \\ University College London
}

\author{
Jihong Lee \\ Seoul National University
}

\begin{abstract}
We study experimentally the role of the network structure of pre-play communication in determination of outcome and behavior in a multiplayer coordination game with conflicting preferences. We explore the trade-off between the efficiency and equity of coordination outcomes and its link to the network structure of communication. Our results show substantial variations in both efficiency and equity of coordination outcomes across networks. While, as expected, increasing the length of communication improves the chance of successful coordination, it also reduces the asymmetry in the distribution of coordinated outcomes. We identify behaviors that explain variations in the distribution of coordinated outcomes both within and across networks. In all treatments, coordination is mostly explained by convergence in communication. (JEL: C70, C92, D61, D63, D82, D83)
\end{abstract}

\section{Introduction}

In numerous social and economic situations, communication offers an effective means to realize the myriad of benefits from coordination, without sacrificing the obvious advantages of decentralized decision making. Coordination failures can mean forgone economies of scale and scope in organizations, as well as being responsible for many macroeconomic events with far-reaching consequences, such as bank runs, market crashes, and contagions (e.g., Diamond and Dybvig 1983; Morris and Shin 1998;

The editor in charge of this paper was George-Marios Angeletos

Acknowledgments: We are grateful to the editor, George-Marios Angeletos, and the anonymous referees for their helpful comments and suggestions. The paper has also benefited from conversations with Matthew Jackson and seminar participants at Bocconi, Bristol, Cambridge, Maastricht, Pittsburgh, Warwick, and IMEBE 2009. We would like to thank Brian Wallace for writing the experimental program, Tom Rutter for helping us to run the experiment, and Sang-Hyun Kim for numerical assistance. We acknowledge the Economic and Social Research Council (UK) via the Centre for Economic Learning and Social Evolution (ELSE) for financial support towards implementing the experiment. Jihong Lee's research was supported by the National Research Foundation of Korea Grant funded by the Korean Government (NRF-2010-327B00086).

E-mail: syngjoo.choi@ucl.ac.uk (Choi); jihonglee@snu.ac.kr (Lee)

This is an open access article under the terms of the Creative Commons Attribution License, which permits use, distribution and reproduction in any medium, provided the original work is properly cited. 
Allen and Gale 2000; Angeletos and La'O 2013), which even prompt global efforts to communicate towards common goals and actions.

Organizations have long recognized the connection between the structure of communication and coordination outcomes. Consider, for instance, the welldocumented coordination failures of the multidivisional structure of General Motors in the 1920s and Alfred Sloan's remedy, which included creating a central office to plan and coordinate overall strategy (e.g., Chandler 1962; Sloan 1990). The subsequent popularity of this type of multidivisional organizational firm demonstrates the roles that communication and coordination have in the success of a firm. However, as found by Sloan himself, and later explored extensively in the organization literature (e.g., Milgrom and Roberts 1992), the overall performance of such an organization critically hinged on fine balancing with regards to the issue of how much authority should be centralized to the corporate headquarters. When the headquarters retained too much power and authority, the operating divisions failed to act in ways that best met their needs, thereby undermining the organization as a whole.

An important source of power is information, and the literature on network analysis (e.g., Wasserman and Faust 1994; Goyal 2007; Jackson 2008) emphasizes that the structure of interaction can matter, especially if it assigns asymmetric advantages among individuals, because this can generate unequal outcomes and payoffs. In the context of an organization, a hierarchical communication structure, which confers a disproportionate informational advantage on the headquarters, might end up coordinating on actions that are most preferred by the headquarters themselves but not by the operating divisions. Despite the coordination, this might lead to a conflict among the divisions and to other wasteful activities.

Putting together the lessons from organizations and the theories of networks, we arrive at the following potential trade-off - a communication structure that improves the chance of coordination might perform poorly in terms of distribution; not only might this be undesirable in itself but it could generate adverse incentives and deadweight losses elsewhere. Indeed, a growing number of empirical studies report evidence of inequity aversion in work places, where relative material payoffs affect individuals' behavior and welfare (e.g., Blinder and Choi 1990; Agell and Lundborg 1995; Bewley 1999; Clark and Oswald 1996; Campbell and Kamlani 1997). If the structure of communication affects coordination, and if the distribution of surplus matters for individual incentives, the tension between efficiency and equity of final outcomes should pose an important consideration for the designer of communication protocol.

In this paper, we explore experimentally the strategic link between the structure of pre-play communication and the outcome of coordination in a decentralized setting. We aim to improve our understanding of how different communication structures affect the outcome of coordination in terms of both efficiency and equity. In order to address these questions, we consider a four-player version of the Battle of the Sexes game, which contains both an element of coordination and an element of conflict. Each player receives a positive payoff if and only if all players coordinate on the same action but there is a different preferred alternative for each player. The symmetric nature of our underlying game is chosen to highlight, if any, the role of the network structure of 
pre-play communication. We are interested in whether and how asymmetry in the communication structure translates to the final outcome.

Prior to playing the above underlying game, the four players engage in multiple periods of structured pre-play communication in which they announce nonbinding, hence cheap talk, messages about their intended actions in the underlying game. Although communication has no direct payoff consequences, the symmetry of players in the underlying game can be broken and coordination can be achieved by implicit agreements, and punishments for deviations, that can arise in the communication stage. The more abundant the opportunities to talk, the more likely the chance of agreement, and hence coordination (e.g., Farrell 1987; Rabin 1994).

In addition to the length of cheap talk, a key variable in our setup concerns the extent to which each player observes the past history of players' announcements, which we interpret as the network structure of pre-play communication. Specifically, at the beginning of each period of communication and the underlying game, a player observes past messages of another player if and only if there is an undirected edge between the two players. Four networks or undirected graphs are considered in our four-player setup: the complete, star, kite, and line networks. In terms of an organization, the complete network can be compared to a horizontal or flat structure under which all the decision makers communicate with each other (e.g., via a committee meeting), while the star network parallels an organization with a central office or leader who is given the sole responsibility to collect information and to determine the overall communication strategy. The other networks can be interpreted as representing communication structures lying in between, with less concentration of informational advantage on a single individual.

In the three networks other than the complete network, players have asymmetric locational characteristics. In particular, some players are linked to only one other player. This type of player is referred to as a periphery, and a player who is linked to a periphery is referred to as a hub. The latter type of players occupy strategically influential locations, in that some players rely entirely on their announcements to learn about others' intentions; thus, they are important objects of our analysis.

Our research questions can be summarized as follows.

QUESTION 1 (Efficiency). How is the likelihood of coordination affected by the length and network structure of pre-play communication?

QUESTION 2 (Equity). How is the distribution of coordinated outcomes affected by the length and network structure of pre-play communication?

The games that we study allow a very rich set of histories and strategies, thereby admitting a large number of equilibria. Thus, standard theory does not offer strong predictions as to whether the coordination outcome will be in any way dependent on the structure of communication. We adopt an experimental approach to address our questions. In the experimental design, we consider treatments that combine the four networks and two different lengths of communication, as well as the underlying game without communication. 
Our experimental results first establish a significant network effect on both the efficiency and equity of the coordination outcome. Significant differences in the coordination rate and the distribution of coordinated actions are observed across networks for each given length of communication. Asymmetric networks tend to generate asymmetric coordination outcomes in favor of hubs. However, our results also demonstrate an important effect of extra communication. While, as expected, an increase in the length of communication improves the chance of successful coordination, it reduces the asymmetry in the distribution of coordinated outcomes. Our experimental evidence thus points to the combined effect of the length and network structure of communication as a determinant of coordination outcome.

We also search for regularities in the subjects' behavior that offer explanations of the variations in the observed frequency and distribution of coordination. Here, in order to handle a vast amount of data on history-dependent actions against the problem of multiple equilibria, we focus on finding evidence of a particular profile of behaviors that naturally capture the strategic advantage of hub players: the hub insists on a single message/action throughout the entire game, referred to as nonswitching behavior, and the other players conform to the hub by playing the hub's choice of action, even after announcing different intentions of their own.

It turns out that this approach explains many differences in observed outcomes across treatments. In particular, our experimental data reveal that the drop in the frequency of coordination on the hub's favorite outcome as we increase the length of communication is induced by more frequent occurrences of switching behavior by the hub. We also identify network-specific behavioral patterns that explain cross-network variations in coordination outcomes.

Finally, in all treatments, the subjects' announcements tend to converge; however, less than unanimity is usually sufficient to ensure corresponding coordination. The observed coordination rates are mostly explained by the frequency of convergence to super-majority or unanimity in the communication stage. Therefore, our data suggest that in real environments, players give more meaning to the messages than standard theory of cheap talk, which always admits inessential multiplicity of equilibria, with many different ways to combine messages to support a given outcome (e.g., Crawford and Sobel 1982). The convergence is more akin to the equilibrium descriptions of Farrell (1987) and Rabin (1994), in which players announce their intended actions and negotiate over different Nash equilibria of the underlying game through the communication stage.

Our paper contributes, above all, to the experimental literature on pre-play communication via cheap talk; see Crawford (1998), Camerer (2003), and Ochs (2008) for related surveys. Within this body of literature, Cooper et al. (1989) consider a twoplayer Battle of the Sexes game with one period of cheap talk, but under two different communication structures: one-way communication versus two-way communication. In the former treatment, only one player can send a message to the other player, whereas the two players send messages simultaneously to each other in the latter treatment. They find that coordination rates are much higher in the one-way treatment than in the two-way treatment, and also that the sender in the one-way treatment sends his 
favorite message, thereby inducing coordination on his favorite outcome, with a very large frequency.

Cooper et al. (1992) and Burton, Loomes, and Sefton (2005) also compare the two different communication structures in other two-player coordination games, in particular, with Pareto-ranked equilibria. Their concern is to see whether cheap talk helps the players to coordinate on the efficient outcome. Blume and Ortmann (2007) test multiplayer coordination games with Pareto-ranked equilibria, but their setup only considers a single communication structure in which players learn the distribution of messages prior to choosing actions. Duffy and Feltovich (2002) explore the role of cheap talk in promoting cooperation and coordination in different games, and compare it to that of dynamic incentives, while Corbae and Duffy (2008) examine the incentives on network formation prior to playing coordination games.

While these papers all consider the effect of pre-play communication on coordination, their settings are limited either in terms of the scope of the network structure or in terms of the communication length; furthermore, the focus of their analyses is only the issue of efficiency. In contrast, our paper explores how the interaction between the horizon and network structure of communication affects coordination; also, we analyze coordination outcome in terms of its distribution as well as its likelihood.

Outside of the economics literature, Kearns et al. (2009) study the role of network structure of communication in a coordination game with conflicting preferences played by a large number of individuals. Although the underlying game and the network/information protocols they study are different from ours, their findings also suggest that some network structures better promote coordination and that certain locations within a network end up obtaining greater earnings than others. A crucial difference between their paper and ours, however, is that they do not investigate the interaction between the time and network effects of communication, as we do in this paper.

Pre-play communication in social networks has been studied in the theoretical models of Chwe (2000), Calvó-Armengol and de Martí (2007, 2009), and Galeotti, Ghiglino, and Squintani (2013), among others. In their setups, prior to playing the underlying game, players simultaneously send messages about their private information to others whom they are linked with (possibly in a directed way). Chwe (2000) and Calvó-Armengol and de Martí (2007, 2009) consider coordination games with common interest and show that coordination can be achieved in networks with fewer links than the complete network. In a setup that allows for conflicting preferences, Galeotti et al. (2013) examine how players' incentives to report the truth and their welfare are related to the network structure. ${ }^{1}$ Thus, the central issue in these papers is the role of network structure on efficiency. In contrast, our paper deals with the distributional issue as well as efficiency. Moreover, unlike theirs, our setup allows for multiple periods of communication, thereby shedding light on the effects of the dynamics of communication.

1. Hagenback and Koessler (2009) consider the issue of endogenous network formation in a coordination setup with pre-play communication. 
Finally, there is a large body of literature on organization design that attempts to theorize the optimal structure of communication when coordination matters. This body of literature, among other things, considers a number of different trade-offs between coordination and noncoordination (e.g., Hart and Moore 2005; Alonso, Dessein, and Matouschek 2008; Hart and Holmström 2010). Although we do not address the issue of optimal design directly, our analysis compares different communication structures along another trade-off, namely, the one between efficiency and equity. Our results suggest that such a trade-off does exist across different networks but this effect becomes diluted as more communication opportunities are introduced.

The rest of the paper is organized as follows. In Section 2, we describe our setup and, in Section 3, we present the experimental design and procedures. In Section 4, we collect and discuss the experimental results. We conclude in Section 5. Online Appendices are also provided to present some details of the equilibrium constructions mentioned Section 2 and some omitted experimental results, as well as sample instructions used in the experiment. ${ }^{2}$

\section{The Setup}

We study games in which multiple players share a common interest to coordinate but each player has his own preferred outcome. The following describes the underlying game. There are four players, indexed by $I=N, E, S, W$, and each player simultaneously and independently chooses an action, $a_{I}$, from a common set $\{n, e, s, w\}$. Let $a=\left(a_{N}, a_{E}, a_{S}, a_{W}\right)$ denote an action profile. Each player obtains a positive payoff if and only if all players choose a single common action. Each player has his preferred action corresponding to his label: player $I$ obtains a higher payoff if all players choose action $i$. Player $I$ 's payoff, $u_{I}(a)$, is given by

$$
u_{I}(a)= \begin{cases}0 & \text { if } a_{I} \neq a_{J} \text { for some } J \neq I, \\ k_{1} & \text { if } a_{I}=a_{J} \neq i \text { for all } J \neq I, \\ k_{2} & \text { if } a_{I}=a_{J}=i \text { for all } J \neq I\end{cases}
$$

where $k_{2}>k_{1}>0$. If there are only two players, the game corresponds to the wellknown Battle of the Sexes. In this sense, the underlying game can be interpreted as a four-player version of Battle of the Sexes.

Prior to playing the underlying game, the players engage in finite periods of pre-play communication, sometimes referred to as the communication stage. Pre-play communication is cheap talk in the usual sense that it is nonbinding and payoffirrelevant. Let $T$ denote the number of periods in the communication stage. In each period $t=1,2, \ldots, T$, each player $I$ simultaneously and independently chooses a message, denoted by $m_{I}^{t}$, from the set $\{n, e, s, w\}$. A message can therefore be interpreted as the player's intended action. We sometimes refer to $T+1$ as the period in which the players engage in the underlying game.

2. Online Appendices are available from authors' websites as well as at the publisher's website. 


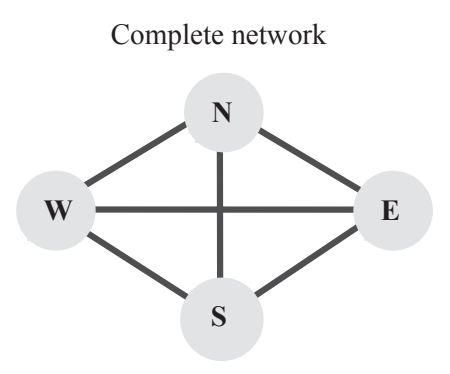

Kite network

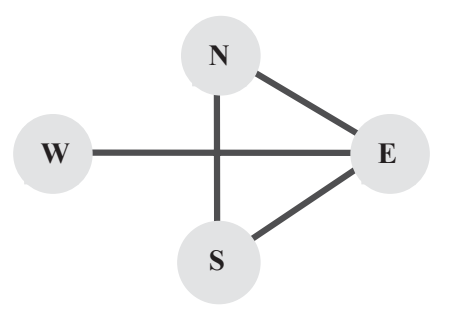

Star network

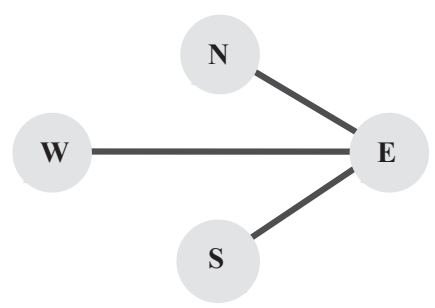

Line network

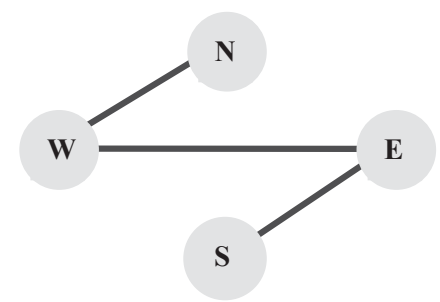

FIGURE 1. Communication networks.

To complete the description of pre-play communication, we specify information available to each player at the beginning of each communication period. In our game, a player may or may not observe the past messages announced by other individuals. We represent the information structure of the game by an undirected graph, or network. If, at the beginning of each period $t \leq T+1$, players $I$ and $J$ observe the history of messages chosen by each other up to, and including, period $t-1$, then we say that the two players can communicate with each other, and illustrate this by an undirected edge or link between the two players. The network structure is common knowledge. We consider four networks (i.e., complete, star, kite, and line), which are illustrated in Figure 1.

In the complete network, each player can communicate with every other player. In the star network, one central player (player $E$ ) can communicate with every other player, while each of the other three players can communicate only with the central player. In the kite network, three players (players $N, E$, and $S$ ) can communicate with each other, while the remaining player (player $W$ ) can communicate only with one of the first three players (player $E$ ). In the line network, two players (players $E$ and $W$ ) can communicate with two other players and each of the two remaining players can communicate only with one of the first two players. The last three networks are sometimes referred to as incomplete networks. ${ }^{3}$

3. Our choice of network structures is not exhaustive of all possible four-player networks. In particular, we do not consider the circle network, which can be obtained by linking nodes $N$ and $S$ in the line network. Because our main interest is on the effect of network asymmetry on the coordination outcome, we have chosen the complete and line networks to serve as symmetric benchmarks for comparison. For 
The main objective of our analysis is to gain an understanding of how network structure affects outcome and behavior. For this purpose, it will be helpful to identify some key positions in the incomplete networks. A periphery is a player who has only one link: $N, S$, and $W$ in the star network, $W$ in the kite network, and $N$ and $S$ in the line network. A hub is a player who is linked to at least one periphery: $E$ in the star network, $E$ in the kite network, and $E$ and $W$ in the line network. We sometimes refer to the entire game that includes both the $T$-period communication stage with a given network and the subsequent underlying game simply as the game with the particular network.

In contrast to Farrell (1987) who analyzes the two-player Battle of the Sexes game with multiple periods of pre-play cheap talk, our games are played by four players, and this generates a very rich set of histories and strategies, thus admitting a large number of equilibria (beyond the usual multiplicity of babbling equilibria). Even in the game with the complete network, a variety of equilibrium communication patterns are possible. For instance, symmetric mixed-strategy equilibria can be constructed such that not only unanimous announcement of a common message but also a super-majority outcome (i.e., all but one player choose the same message) or a majority outcome (i.e., only two players choose the same message) constitutes an implicit agreement to play the corresponding Nash equilibrium in the underlying game. Another source of multiplicity of symmetric equilibria in our four-player games is the possibility of partial agreements; that is, the players may treat certain communication outcomes as an interim basis for further negotiation. ${ }^{4}$

\section{Experimental Procedure}

The experiment was run at the Experimental Laboratory of the Centre for Economic Learning and Social Evolution (ELSE) at University College London (UCL) between May 2008 and November 2008, and between May 2011 and June 2011. The subjects in the experiment were recruited from the ELSE pool of human subjects, mainly including UCL undergraduate students across all disciplines. Each subject participated in only one of the experimental sessions. After subjects had read the instructions, the instructions were read aloud by an experimental administrator. Throughout the experiment, we ensured anonymity and effective isolation of subjects in order to minimize any interpersonal influences that could stimulate cooperation. Each experimental session lasted between one hour and one and a half hours. The experiment was computerized and conducted using the experimental software z-Tree developed by Fischbacher (2007). Sample instructions are reported in Online Appendix II.

some measures of network asymmetry, such as network centrality, see Wasserman and Faust (1994), for instance.

4. In Online Appendix I, we provide detailed examples of multiple equilibria along these lines under the complete network. The equilibrium features that we address here are also present in games with other networks, although in those cases equilibrium characterization is further complicated by imperfect information. 
TABLE 1. Summary of experimental treatments.

\begin{tabular}{lccccc}
\hline & & \multicolumn{3}{c}{ Session } \\
\cline { 3 - 5 } Network & $T$ & 1 & 2 & 3 & Total \\
\hline Complete & 2 & $16 / 80$ & $16 / 80$ & $16 / 80$ & $48 / 240$ \\
\multirow{2}{*}{ Star } & 5 & $20 / 100$ & $16 / 80$ & $16 / 80$ & $52 / 260$ \\
& 2 & $16 / 80$ & $16 / 80$ & $16 / 80$ & $48 / 240$ \\
Kite & 5 & $16 / 80$ & $16 / 80$ & $16 / 80$ & $48 / 240$ \\
\multirow{2}{*}{ Line } & 2 & $16 / 80$ & $16 / 80$ & $16 / 80$ & $48 / 240$ \\
\multirow{2}{*}{ No communication } & 5 & $20 / 100$ & $16 / 80$ & $16 / 80$ & $52 / 240$ \\
& 2 & $16 / 80$ & $16 / 80$ & $16 / 80$ & $48 / 240$ \\
& 5 & $16 / 80$ & $16 / 80$ & $16 / 80$ & $48 / 240$ \\
& & $20 / 150$ & $16 / 120$ & $12 / 90$ & $48 / 360$ \\
\hline
\end{tabular}

We studied the game with four network structures (complete, star, kite and line) and two lengths of pre-play communication- $T=2$ (short) and $T=5$ (long) -in addition to the one-shot game with no communication $(T=0)$, which is included to check whether communication indeed has a role. ${ }^{5}$ A single treatment consisting of a pair of networks and $T$ was used for each session, and each treatment was used for three sessions. Thus, there were in total nine treatments and 27 experimental sessions. Either 16 or 20 subjects participated in each session, which consisted of 20 independent rounds, except for the no-communication treatment whose sessions consisted of 30 rounds each. In one session of the no-communication treatment, 12 subjects participated. Thus, we have in total 440 subjects who participated in the experiment. Table 1 summarizes the experimental design and the amount of experimental data. The first number in each cell is the number of subjects and the second is the number of group observations in each treatment.

In each session, the network positions were labeled $N, E, S$, or $W$. Onefourth of the subjects were randomly designated as type- $N$ participants, one-fourth as type- $E$ participants, one-fourth as type- $S$ participants, and one-fourth as type$W$ participants. Each subject's type remained constant throughout the session. ${ }^{6}$ In each round, the subjects were randomly formed into four-person groups. The groups formed in each round were independent of the groups formed in any of the other rounds.

Each round was divided into two stages: a communication stage, which consists of $T$ (either 2 or 5 ) decision-turns, and an action stage, which consists of a single decisionturn. In the no-communication treatment, there was only an action stage in each round.

5. The choice of communication lengths $(T=2$ and $T=5)$ in our experimental design is partially motivated by the theoretical considerations appearing in Online Appendix I. There, we construct sequential equilibria of the three incomplete networks in which the hub obtains greater payoffs than the other players. These equilibrium constructions require that $T \geq 3$.

6. This design choice is irrelevant when all positions are symmetric (i.e., in the complete network and no-communication treatments). For the other treatments, we want to avoid any possibility that alternating roles within a session makes subjects confused and deters them from applying a consistent decision rule across rounds. 
In the action stage, four actions were available: $n, e, s$, and $w$. The communication stage that preceded the action stage involved each participant sending messages. In each decision-turn of the communication stage, each participant was asked to choose a message from $n, e, s$, and $w$, which were labeled by the same letters as the actions available in the action stage. It was illustrated that a message may indicate a subject's intended action in the subsequent action stage but the subject does not have to follow that message when it comes to making an action choice. When every participant in the group had made his or her decision, each participant received the messages chosen by the participants to whom he or she was connected in the network. This completed the first decision-turn of the communication stage. This process was repeated in the remaining decision-turns of the communication stage.

When the communication stage ended, each participant was asked to choose an action out of the four possible actions without knowing the actions selected by other participants. After every participant had made a decision in the action stage, the computer informed subjects of the actions chosen by all the participants in the group and their earnings. It was illustrated and emphasized that the earnings in each round are determined only by the actions chosen in the action stage and the messages chosen in the preceding communication stage are entirely irrelevant to earnings. After each subject observed the results of the first round, the second round started with the computer randomly forming new groups of four participants with distinct types. This process was repeated until all 20 rounds were completed.

Earnings were calculated in terms of tokens and then exchanged into British pounds, where each token was worth $£ 0.50$. The earnings in each round were determined as follows. If all participants in the group chose a common action, a participant whose label corresponded to the letter of the common action received three tokens while the other participants received one token each. Otherwise, all participants received no token. Thus, the total payment to a subject was equal to $£ 0.50$ times the total number of tokens earned over 20 rounds (30 rounds in the no-communication treatment), plus a $£ 5$ participation fee. The average payment was about $£ 13$. Subjects received their payments privately at the end of the session.

\section{Experimental Results}

\subsection{Coordination Outcomes}

We begin our analysis of the experimental data by examining the final outcomes of coordination in each treatment. As summarized in the Introduction, the focus of our interest lies in the impact of our treatments on both efficiency and equity of the outcomes of the underlying game. To address the issue of efficiency, we consider the rate of coordination; for equity, we examine the distribution of coordinated actions.

Table 2 reports the coordination rate for each session as well as for the pooled data under each treatment. We also report the results of the statistical test of equality of coordination rates across each pair of treatments, both for the pooled data (Table 3(a)) and for the session-level data (Table 3(b)). 
TABLE 2. Frequencies of coordination.

\begin{tabular}{|c|c|c|c|c|c|c|c|c|c|}
\hline \multirow[b]{2}{*}{ Session } & \multicolumn{2}{|c|}{ Complete } & \multicolumn{2}{|c|}{ Star } & \multicolumn{2}{|c|}{ Kite } & \multicolumn{2}{|c|}{ Line } & \multirow{2}{*}{$\begin{array}{c}\text { No } \\
\text { communication }\end{array}$} \\
\hline & $T=2$ & $T=5$ & $T=2$ & $T=5$ & $T=2$ & $T=5$ & $T=2$ & $T=5$ & \\
\hline 1 & $\begin{array}{l}0.65 \\
(80)\end{array}$ & $\begin{array}{c}0.70 \\
(100)\end{array}$ & $\begin{array}{l}0.64 \\
(80)\end{array}$ & $\begin{array}{l}0.73 \\
(80)\end{array}$ & $\begin{array}{l}0.56 \\
(80)\end{array}$ & $\begin{array}{c}0.68 \\
(100)\end{array}$ & $\begin{array}{l}0.28 \\
(80)\end{array}$ & $\begin{array}{l}0.50 \\
(80)\end{array}$ & $\begin{array}{c}0.05 \\
(150)\end{array}$ \\
\hline 2 & $\begin{array}{l}0.75 \\
(80)\end{array}$ & $\begin{array}{l}0.81 \\
(80)\end{array}$ & $\begin{array}{l}0.54 \\
(80)\end{array}$ & $\begin{array}{l}0.56 \\
(80)\end{array}$ & $\begin{array}{l}0.34 \\
(80)\end{array}$ & $\begin{array}{l}0.68 \\
(80)\end{array}$ & $\begin{array}{l}0.31 \\
(80)\end{array}$ & $\begin{array}{l}0.60 \\
(80)\end{array}$ & $\begin{array}{c}0.06 \\
(120)\end{array}$ \\
\hline 3 & $\begin{array}{l}0.83 \\
(80)\end{array}$ & $\begin{array}{l}0.80 \\
(80)\end{array}$ & $\begin{array}{l}0.50 \\
(80)\end{array}$ & $\begin{array}{l}0.70 \\
(80)\end{array}$ & $\begin{array}{l}0.65 \\
(80)\end{array}$ & $\begin{array}{l}0.61 \\
(80)\end{array}$ & $\begin{array}{l}0.41 \\
(80)\end{array}$ & $\begin{array}{l}0.59 \\
(80)\end{array}$ & $\begin{array}{l}0.14 \\
(90)\end{array}$ \\
\hline All & $\begin{array}{l}0.74 \\
(240)\end{array}$ & $\begin{array}{l}0.77 \\
(260)\end{array}$ & $\begin{array}{l}0.56 \\
(240)\end{array}$ & $\begin{array}{l}0.66 \\
(240)\end{array}$ & $\begin{array}{l}0.52 \\
(240)\end{array}$ & $\begin{array}{l}0.66 \\
(260)\end{array}$ & $\begin{array}{l}0.33 \\
(240)\end{array}$ & $\begin{array}{l}0.56 \\
(240)\end{array}$ & $\begin{array}{c}0.08 \\
(360)\end{array}$ \\
\hline
\end{tabular}

TABLE 3. Test of pairwise equality of coordination rates.

\begin{tabular}{|c|c|c|c|c|c|c|c|c|c|c|}
\hline & & \multicolumn{2}{|c|}{ Complete } & \multicolumn{2}{|c|}{ Star } & \multicolumn{2}{|c|}{ Kite } & \multicolumn{2}{|c|}{ Line } & \multirow{2}{*}{$\begin{array}{c}\text { No } \\
\text { communication }\end{array}$} \\
\hline & & 2 & 5 & 2 & 5 & 2 & 5 & 2 & 5 & \\
\hline \multicolumn{11}{|c|}{ (a) Wilcoxon (Mann-Whitney) rank-sum test with the pooled data } \\
\hline \multirow[t]{2}{*}{ Complete } & 2 & - & $0.539^{a}$ & $0.000^{b}$ & 0.058 & $0.000^{b}$ & 0.041 & $0.000^{b}$ & 0.000 & 0.000 \\
\hline & 5 & - & - & 0.000 & $0.011^{b}$ & 0.000 & $0.007^{b}$ & 0.000 & $0.000^{b}$ & 0.000 \\
\hline \multirow[t]{2}{*}{ Star } & 2 & - & - & - & $0.019^{a}$ & $0.361^{b}$ & 0.023 & $0.000^{b}$ & 0.927 & 0.000 \\
\hline & 5 & - & - & - & - & 0.001 & $0.910^{b}$ & 0.000 & $0.025^{b}$ & 0.000 \\
\hline \multirow[t]{2}{*}{ Kite } & 2 & - & - & - & - & - & $0.001^{a}$ & $0.000^{b}$ & 0.314 & 0.000 \\
\hline & 5 & - & - & - & - & - & - & 0.000 & $0.029^{b}$ & 0.000 \\
\hline \multirow[t]{2}{*}{ Line } & 2 & - & - & - & - & - & - & - & $0.000^{a}$ & 0.000 \\
\hline & 5 & - & - & - & - & - & - & - & - & 0.000 \\
\hline \multicolumn{2}{|c|}{ No communication } & - & - & - & - & - & - & - & - & - \\
\hline \multicolumn{11}{|c|}{ (b) Pairwise $t$-test with the session average data } \\
\hline \multirow[t]{2}{*}{ Complete } & 2 & - & $0.662^{a}$ & $0.048^{b}$ & 0.331 & $0.101^{b}$ & 0.195 & $0.003^{b}$ & 0.040 & 0.000 \\
\hline & 5 & - & - & 0.017 & $0.155^{b}$ & 0.063 & $0.051^{b}$ & 0.001 & $0.012^{b}$ & 0.000 \\
\hline \multirow[t]{2}{*}{ Star } & 2 & - & - & - & $0.185^{a}$ & $0.703^{b}$ & 0.104 & $0.018^{b}$ & 0.940 & 0.001 \\
\hline & 5 & - & - & - & - & 0.241 & $0.909^{b}$ & 0.007 & $0.168^{b}$ & 0.001 \\
\hline \multirow[t]{2}{*}{ Kite } & 2 & - & - & - & - & - & $0.219^{a}$ & $0.146^{b}$ & 0.665 & 0.012 \\
\hline & 5 & - & - & - & - & - & - & 0.002 & $0.071^{b}$ & 0.000 \\
\hline \multirow[t]{2}{*}{ Line } & 2 & - & - & - & - & - & - & - & $0.011^{a}$ & 0.008 \\
\hline & 5 & - & - & - & - & - & - & - & - & 0.000 \\
\hline \multicolumn{2}{|c|}{ No communication } & - & - & - & - & - & - & - & - & - \\
\hline
\end{tabular}

Notes: Each cell reports the $p$-value from the Wilcoxon (Mann-Whitney) rank-sum test in Table 3(a) and the pairwise $t$-test in Table 3(b) on coordination rates between two treatments. The test results in Table 3(a) are made by pooling the data, and those in Table 3(b) are done by treating the coordination rate in a session as an independent observation. ${ }^{a}$ A pairwise test between $T=2$ and $T=5$ within a network. ${ }^{b}$ A pairwise test between two networks given $T$.

The pooled-data analysis yields the following results. First, the coordination rate in every treatment with communication is substantially higher than that in the nocommunication treatment (see in the last column in Table 3(a) for the statistical results on pairwise comparison). ${ }^{7}$ Second, given each $T$, the highest coordination rate is obtained in the complete network, followed by similar rates in the star and kite networks, and then the distinctly lowest rate in the line network (see the values labeled with a superscript $b$ in Table 3(a)). Third, given each network, when communication becomes longer, the coordination rate increases significantly in all networks except for the complete network (see the values labeled with a superscript $a$ in Table 3(a)).

7. Our experiment employs a random matching design with fixed roles. Thus, for the statistical validity of pairwise comparison in the pooled data, we assume independence of each game observation within each session. However, correlation across games would underestimate standard errors. 


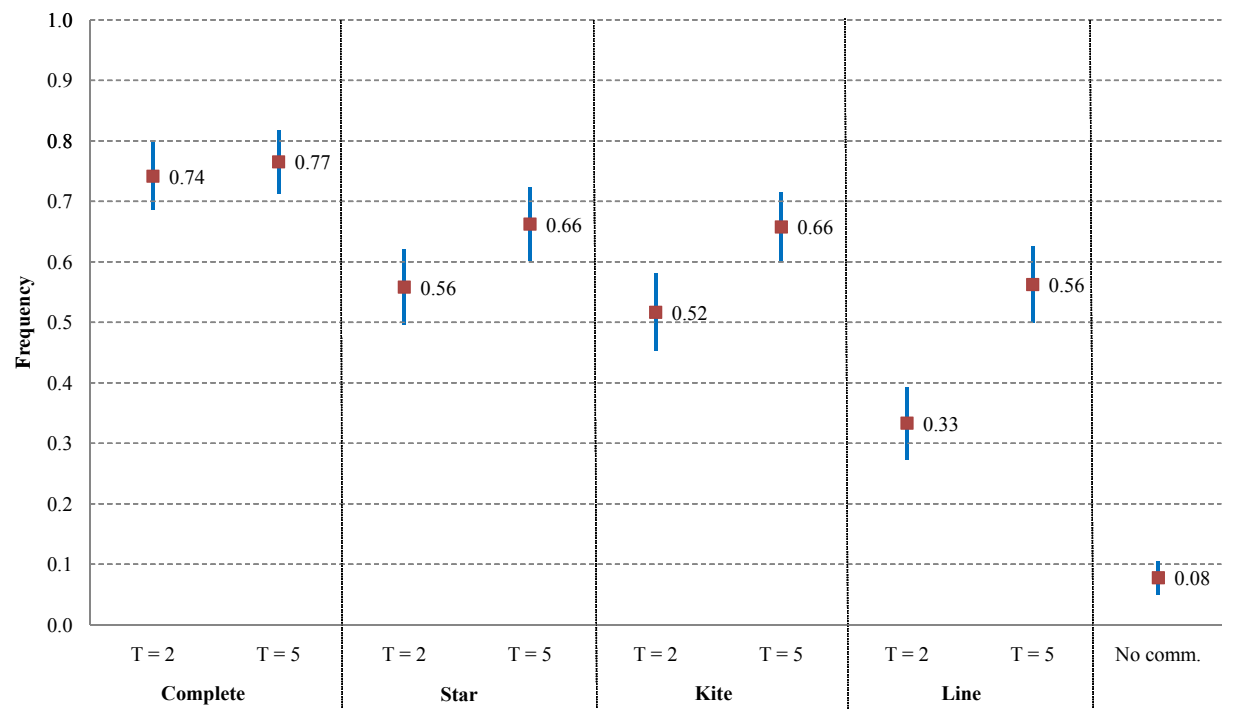

FIGURE 2. Frequencies of coordination (sample means and $95 \%$ confidence intervals).

Let us illustrate these findings in Figure 2, where we plot the coordination rates across treatments with a $95 \%$ confidence interval.

Next, we turn to session-level analysis by treating each session average as a single, independent observation. The session-level data reveal patterns that are qualitatively similar to the variations in the coordination rate for the pooled data, although fewer differences in coordination rates are statistically significant because of the small samples. First, the effect of communication in every treatment relative to the nocommunication treatment is statistically significant even in the session level (see the last column in Table 3(b)). Second, fixing $T$, we cannot reject at a 5\% significance level, the equality of coordination rates between the complete and kite networks when $T=2$ and between the complete, star, and kite networks when $T=5$ (see the values labeled with a superscript $b$ in Table 3(b)). Third, fixing the network, the positive effect of extra communication is no longer significant in all networks except for the line network (see the values labeled with a superscript $a$ in Table 3(b)).

Overall, we summarize these findings as follows.

\section{RESUlt 1 (Efficiency).}

1. Coordination rates are higher in treatments with communication than in the treatment with no communication.

2. Given any time treatment $T$, coordination rates are highest in the complete network, followed by the star and kite networks, and then by the line network.

3. Given any network treatment other than the complete network, the coordination rate increases from $T=2$ to $T=5$. 
TABLE 4. Frequencies of coordinated actions.

\begin{tabular}{|c|c|c|c|c|c|c|c|c|}
\hline \multirow[b]{2}{*}{ Network } & \multirow[b]{2}{*}{$T$} & \multirow[b]{2}{*}{ Session } & \multicolumn{4}{|c|}{ Action } & \multirow[b]{2}{*}{ No. obs. } & \multirow[b]{2}{*}{$p$-value } \\
\hline & & & $n$ & $e$ & $s$ & $w$ & & \\
\hline \multirow[t]{8}{*}{ Complete } & 2 & 1 & 0.19 & 0.33 & 0.23 & 0.25 & 52 & 0.57 \\
\hline & & 2 & 0.28 & 0.25 & 0.25 & 0.22 & 60 & 0.91 \\
\hline & & 3 & 0.21 & 0.29 & 0.21 & 0.29 & 66 & 0.68 \\
\hline & & All & 0.23 & 0.29 & 0.23 & 0.25 & 178 & 0.68 \\
\hline & 5 & 1 & 0.24 & 0.27 & 0.24 & 0.24 & 70 & 0.98 \\
\hline & & 2 & 0.26 & 0.20 & 0.25 & 0.29 & 65 & 0.76 \\
\hline & & 3 & 0.23 & 0.30 & 0.25 & 0.22 & 64 & 0.83 \\
\hline & & All & 0.25 & 0.26 & 0.25 & 0.25 & 199 & 1.00 \\
\hline \multirow[t]{8}{*}{ Star } & 2 & 1 & 0.10 & 0.76 & 0.06 & 0.08 & 51 & 0.00 \\
\hline & & 2 & 0.09 & 0.72 & 0.09 & 0.09 & 43 & 0.00 \\
\hline & & 3 & 0.20 & 0.45 & 0.13 & 0.23 & 40 & 0.02 \\
\hline & & All & 0.13 & 0.66 & 0.09 & 0.13 & 134 & 0.00 \\
\hline & 5 & 1 & 0.19 & 0.45 & 0.19 & 0.17 & 58 & 0.01 \\
\hline & & 2 & 0.16 & 0.53 & 0.16 & 0.16 & 45 & 0.00 \\
\hline & & 3 & 0.11 & 0.63 & 0.09 & 0.18 & 56 & 0.00 \\
\hline & & All & 0.15 & 0.53 & 0.14 & 0.17 & 159 & 0.00 \\
\hline \multirow[t]{8}{*}{ Kite } & 2 & 1 & 0.18 & 0.56 & 0.16 & 0.11 & 45 & 0.00 \\
\hline & & 2 & 0.07 & 0.78 & 0.11 & 0.04 & 27 & 0.00 \\
\hline & & 3 & 0.23 & 0.54 & 0.12 & 0.12 & 52 & 0.00 \\
\hline & & All & 0.18 & 0.60 & 0.13 & 0.10 & 124 & 0.00 \\
\hline & 5 & 1 & 0.16 & 0.34 & 0.21 & 0.29 & 68 & 0.15 \\
\hline & & 2 & 0.24 & 0.35 & 0.19 & 0.22 & 54 & 0.34 \\
\hline & & 3 & 0.16 & 0.31 & 0.27 & 0.27 & 49 & 0.54 \\
\hline & & All & 0.19 & 0.33 & 0.22 & 0.26 & 171 & 0.04 \\
\hline \multirow[t]{8}{*}{ Line } & 2 & 1 & 0.27 & 0.27 & 0.18 & 0.27 & 22 & 0.91 \\
\hline & & 2 & 0.04 & 0.72 & 0.04 & 0.20 & 25 & 0.00 \\
\hline & & 3 & 0.00 & 0.15 & 0.03 & 0.82 & 33 & 0.00 \\
\hline & & All & 0.09 & 0.36 & 0.08 & 0.48 & 80 & 0.00 \\
\hline & 5 & 1 & 0.23 & 0.30 & 0.18 & 0.30 & 40 & 0.61 \\
\hline & & 2 & 0.21 & 0.25 & 0.23 & 0.31 & 48 & 0.76 \\
\hline & & 3 & 0.19 & 0.40 & 0.13 & 0.28 & 47 & 0.04 \\
\hline & & All & 0.21 & 0.32 & 0.18 & 0.30 & 135 & 0.06 \\
\hline \multirow{4}{*}{\multicolumn{2}{|c|}{ No communication }} & 1 & 0.75 & 0.25 & 0.00 & 0.00 & 8 & 0.00 \\
\hline & & 2 & 0.29 & 0.00 & 0.71 & 0.00 & 7 & 0.00 \\
\hline & & 3 & 0.85 & 0.08 & 0.08 & 0.00 & 13 & 0.00 \\
\hline & & All & 0.68 & 0.11 & 0.21 & 0.00 & 28 & 0.00 \\
\hline
\end{tabular}

Note: A $p$-value is from the chi-square nonparametric test with null hypothesis that the action frequencies are uniformly distributed.

Next, in Table 4, we present the distribution of coordinated outcomes in the underlying game per session as well as for the pooled data, along with the $p$-values from the chi-square nonparametric test for uniform distribution.

Figure 3 illustrates graphically, conditional on coordination, whose preferred outcome was coordinated on for the pooled data.

We observe a notable effect of both the length and network structure of communication on the distribution of coordinated outcomes. First, while the distribution of coordinated outcomes in the complete network is close to uniform, 


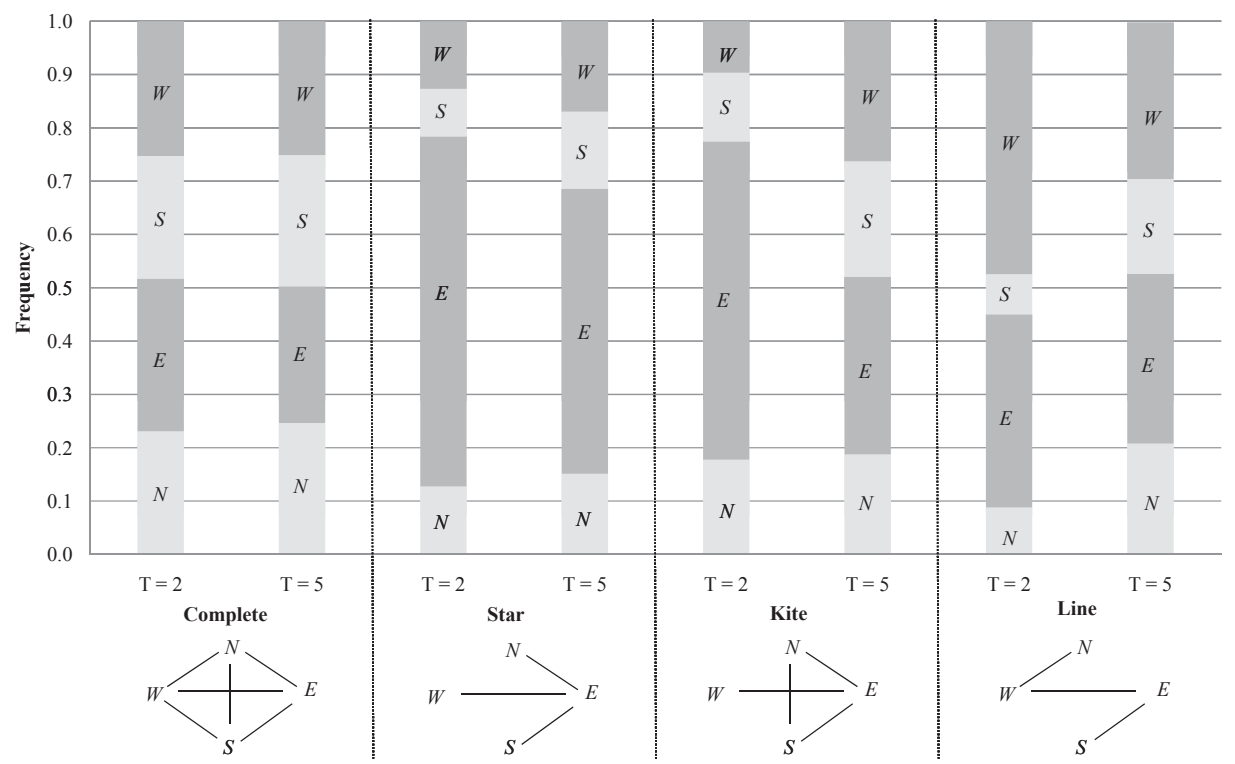

FIGURE 3. Frequencies of coordinated actions.

both when $T=2$ and when $T=5$, in all three incomplete networks, the distributions appear significantly asymmetric in favor of the hub ( $E$ in star and kite; $E$ and $W$ in line). Thus, the data confirm the intuition that network asymmetry matters; in particular, the symmetry of the underlying game is broken in favor of the hub.

Second, both when $T=2$ and when $T=5$, the likelihood of coordination on action $e$ is higher in the star network than in the kite network. This appears to suggest that an additional link between $N$ and $S$ in the kite network reduces the hub player $E$ 's strategic advantage. We investigate this issue further in Section 4.3.

Third, and most interestingly, there is strong evidence of the time effect in all three incomplete networks. Here, the longer the players engage in cheap talk, the less frequently they coordinate on the favorite action of a hub. Furthermore, in the star and line networks, the likelihood of coordination on each of the peripheries appears to increase by equal proportion as we go from $T=2$ to $T=5$; in the kite network, however, the decrease in the likelihood of coordination on the hub $E$ 's favorite action is matched disproportionately by an increase in the likelihood of the periphery $W$ 's favorite action. This observation is consistent with the symmetrybreaking role of network structure. The frequent occurrence of action $w$ in the kite network when $T=5$ can be justified by the fact that $W$ is the only player with a single link.

For both time treatments, and for each session and the pooled data, we cannot statistically reject the uniform distribution in the complete network while rejecting the null in the star network. In the kite network, the distribution is statistically different from uniform when $T=2$ but we cannot reject the null for each session when $T=5$ 
(although we reject it for the pooled data). Similarly, in the line network, the null of uniform distribution is mostly rejected when $T=2$ but mostly not when $T=5$.

In summary, the data support the following.

RESUlT 2 (Equity).

1. We observe the following both when $T=2$ and when $T=5$.

(a) In the complete network, the distribution of coordinated actions is close to uniform.

(b) In the star and kite networks, the distribution of coordinated actions is concentrated on action ; in the line network, the distribution is concentrated on actions $e$ and $w$.

2. Given any $T$, the frequency of coordination on action e is higher in the star network than in the kite network.

3. Given any incomplete network, the distribution of coordinated actions is less asymmetric when $T=5$ than when $T=2$.

Despite the multiplicity of equilibria, our experimental results strongly support regularity of certain patterns in outcomes. The network structure of communication does matter for both efficiency and equity of coordination outcomes. However, the length of communication also plays an important role. Our results suggest that allowing the players to communicate longer will not only improve efficiency but also make the coordination outcome more equitable in the networks that produce asymmetric coordination outcomes. ${ }^{8}$

\subsection{Communication and Coordination}

Next, we examine the play of the communication stage and relate the dynamics of communication to coordination outcomes. First, we consider the form of agreement that leads to coordination. Table 5 presents the likelihood of coordination (on any action) in the underlying game contingent on each possible outcome in the last period of the communication stage, together with the number of observations for each communication outcome. ${ }^{9}$

In the complete network, communication outcomes are divided into five categories: unanimity, super-majority, majority, tied-majority, and complete disagreement. Unanimity is an outcome in which all four players announce the same message; super-majority is an outcome in which all but one player choose the same message;

8. Our analysis in Tables $2-4$ pools the data from all rounds in each session for a given treatment. We have conducted a parallel analysis of Tables $2-4$ by considering the first-half rounds and second-half rounds of the data separately. Our results, which appear in Online Appendix III.1 (Tables 1A and 2A), suggest that there is little evidence of behavioral adjustments over rounds in the data.

9. In what follows, all our results are based on pooled data. 
TABLE 5. Relation between last-period communication and coordination.

\begin{tabular}{|c|c|c|c|c|c|}
\hline & & $T=$ & & $T=$ & \\
\hline & ome & Coord. freq. & No. obs. & Coord. freq. & No. obs. \\
\hline (a) Complete & & & & & \\
\hline Unanimity & & 0.96 & 80 & 0.96 & 121 \\
\hline Super-majority & & 0.83 & 70 & 0.66 & 101 \\
\hline Majority & & 0.80 & 54 & 0.56 & 27 \\
\hline Tied-majority & & 0.00 & 13 & 0.00 & 6 \\
\hline Complete disagre & ment & 0.00 & 23 & 0.20 & 5 \\
\hline Total & & 0.74 & 240 & 0.77 & 260 \\
\hline (b) Star & & & & & \\
\hline Unanimity & & 0.89 & 47 & 0.90 & 77 \\
\hline Super-majority & $\begin{array}{c}\text { NES/NEW/ESW } \\
\text { NSW }\end{array}$ & $\begin{array}{l}0.61 \\
0.00\end{array}$ & $\begin{array}{c}93 \\
2\end{array}$ & $\begin{array}{l}0.66 \\
0.00\end{array}$ & $\begin{array}{c}92 \\
2\end{array}$ \\
\hline Majority & $\begin{array}{l}\text { NE/EW/ES } \\
\text { NS/NW/SW }\end{array}$ & $\begin{array}{l}0.39 \\
0.50\end{array}$ & $\begin{array}{c}61 \\
8\end{array}$ & $\begin{array}{l}0.45 \\
0.29\end{array}$ & $\begin{array}{c}42 \\
7\end{array}$ \\
\hline $\begin{array}{l}\text { Others } \\
\text { Total }\end{array}$ & & $\begin{array}{l}0.24 \\
0.56\end{array}$ & $\begin{array}{c}29 \\
240\end{array}$ & $\begin{array}{l}0.40 \\
0.66\end{array}$ & $\begin{array}{c}20 \\
240\end{array}$ \\
\hline (c) Kite & & & & & \\
\hline Unanimity & & 0.96 & 27 & 0.94 & 85 \\
\hline Super-majority & $\begin{array}{c}\text { NES/NEW/ESW } \\
\text { NSW }\end{array}$ & $\begin{array}{c}0.71 \\
-\end{array}$ & $\begin{array}{c}87 \\
0\end{array}$ & $\begin{array}{l}0.73 \\
0.00\end{array}$ & $\begin{array}{c}99 \\
4\end{array}$ \\
\hline Majority & $\begin{array}{l}\text { NE/EW/ES } \\
\text { NS/NW/SW }\end{array}$ & $\begin{array}{l}0.40 \\
0.04\end{array}$ & $\begin{array}{l}63 \\
25\end{array}$ & $\begin{array}{l}0.39 \\
0.07\end{array}$ & $\begin{array}{l}36 \\
15\end{array}$ \\
\hline $\begin{array}{l}\text { Others } \\
\text { Total }\end{array}$ & & $\begin{array}{l}0.26 \\
0.52\end{array}$ & $\begin{array}{c}38 \\
240\end{array}$ & $\begin{array}{l}0.19 \\
0.66\end{array}$ & $\begin{array}{c}21 \\
260\end{array}$ \\
\hline (d) Line & & & & & \\
\hline Unanimity & & 1.00 & 26 & 1.00 & 90 \\
\hline Super-majority & $\begin{array}{l}\text { NEW/ESW } \\
\text { NSW/NES }\end{array}$ & $\begin{array}{l}0.53 \\
0.23\end{array}$ & $\begin{array}{l}74 \\
31\end{array}$ & $\begin{array}{l}0.64 \\
0.00\end{array}$ & $\begin{array}{c}61 \\
7\end{array}$ \\
\hline Majority & $\begin{array}{c}\text { EW } \\
\text { NW/ES/NE/SW } \\
\text { NS }\end{array}$ & $\begin{array}{l}0.36 \\
0.02 \\
0.00\end{array}$ & $\begin{array}{c}11 \\
52 \\
6\end{array}$ & $\begin{array}{l}0.50 \\
0.00 \\
0.50\end{array}$ & $\begin{array}{c}8 \\
32 \\
2\end{array}$ \\
\hline Others & & 0.08 & 40 & 0.03 & 40 \\
\hline Total & & 0.33 & 240 & 0.56 & 240 \\
\hline
\end{tabular}

majority is an outcome in which only two players announce the same message; tiedmajority is an outcome with two distinct pairs of two players who choose the same message; and complete disagreement is an outcome in which each player announces a distinct message. In the incomplete (star, kite, and line) networks, we divide supermajority and majority further by identifying whether such an outcome includes the hub player(s). For example, a super-majority outcome NES in the star network represents players $N, E$, and $S$ choosing the same message in period $T .{ }^{10}$

10. Because of the small number of observations, tied-majority and complete disagreement are treated as one outcome in each of the incomplete networks. 
TABLE 6. Frequencies of unanimity and super-majority.

\begin{tabular}{|c|c|c|c|c|c|c|c|}
\hline \multirow[b]{2}{*}{ Network } & \multirow[b]{2}{*}{$T$} & \multicolumn{5}{|c|}{ Time $(t)$} & \multirow{2}{*}{$\begin{array}{l}\text { Coordination } \\
\text { frequency }\end{array}$} \\
\hline & & 1 & 2 & 3 & 4 & 5 & \\
\hline \multirow[t]{3}{*}{ Complete } & 2 & 0.17 & 0.63 & - & - & - & 0.74 \\
\hline & & $(-)$ & $(0.46)$ & - & - & - & \\
\hline & 5 & $\begin{array}{c}0.08 \\
(-)\end{array}$ & $\begin{array}{c}0.32 \\
(0.23)\end{array}$ & $\begin{array}{c}0.50 \\
(0.19)\end{array}$ & 0.67 & $\begin{array}{c}0.85 \\
(019)\end{array}$ & 0.77 \\
\hline \multirow[t]{4}{*}{ Star } & 2 & 0.18 & 0.58 & - & - & - & 0.56 \\
\hline & & $(-)$ & $(0.40)$ & - & - & - & \\
\hline & 5 & 0.07 & 0.29 & 0.39 & 0.47 & 0.70 & 0.66 \\
\hline & & $(-)$ & $(0.23)$ & $(0.10)$ & $(0.08)$ & $(0.24)$ & \\
\hline \multirow[t]{4}{*}{ Kite } & 2 & 0.12 & 0.48 & - & - & - & 0.52 \\
\hline & & $(-)$ & $(0.35)$ & - & - & - & \\
\hline & 5 & 0.07 & 0.20 & 0.30 & 0.47 & 0.71 & 0.66 \\
\hline & & $(-)$ & $(0.14)$ & (0.09) & $(0.18)$ & $(0.24)$ & \\
\hline \multirow[t]{4}{*}{ Line } & 2 & 0.10 & 0.42 & - & - & - & 0.33 \\
\hline & & $(-)$ & $(0.32)$ & - & - & - & \\
\hline & 5 & 0.04 & 0.18 & 0.29 & 0.45 & 0.63 & 0.56 \\
\hline & & $(-)$ & (0.13) & $(0.12)$ & $(0.16)$ & $(0.18)$ & \\
\hline
\end{tabular}

Notes: A number in parentheses is the marginal change from period $t-1$ to period $t$. For incomplete networks, we consider only super-majority including the hub(s).

There is a strong relation between what happens in the last period of the communication stage and coordination in the underlying game across all treatments; a wider consensus improves the chance of coordination. Unanimity leads to coordination almost with certainty in all treatments. Super-majority is very likely to induce coordination in most of the treatments, one possible exception being the line network with $T=2$. Notice here that almost all super-majority outcomes in period $T$ include the hub(s), except in the line network with $T=2$. Although majority also leads to coordination with a large probability in the complete network, especially when $T=2$, this correlation does not exceed a half in all other network treatments.

Another observation from Table 5 is the high frequencies of unanimity and supermajority in the last period of communication. For instance, in the complete network, the subjects reached super-majority or unanimity by period $T$ in $63 \%$ of observations when $T=2(150 / 240)$ and $85 \%$ of observations when $T=5(222 / 260)$. This leads us to Table 6 , which reports the frequency of unanimity or super-majority occurring in each period $t \leq T$.

There is a clear pattern of convergence towards unanimity or super-majority in all treatments. The chance of one of these two types of communication outcome in the first period is low, ranging from 0.04 (line network with $T=5$ ) and 0.18 (star network with $T=2$ ), but it increases monotonically over time in all treatments. Moreover, in all treatments, the chance of eventual coordination (the last column) is very close to the chance of successfully reaching such an outcome. 
We summarize these findings from Tables 5 and 6, as follows.

RESULT 3. We observe the following patterns in all treatments.

1. A greater degree of agreement in the last period of communication is associated with a greater likelihood of coordination.

2. The outcome path in the communication stage converges towards super-majority or unanimity.

3. The coordination rate is mostly explained by the frequency of convergence to super-majority or unanimity in the communication stage.

These observations indicate the following. First, the link between the form of agreement and coordination suggests that the experimental subjects give more meaning to the messages than standard theory of cheap talk in which inessential equilibria can be constructed with arbitrary sequences of messages to support any given equilibrium outcome (e.g., Crawford and Sobel 1982). Second, the convergence towards tighter consensus in the communication stage could be interpreted as the players announcing intended actions and bargaining over different equilibria of the underlying game, akin to the equilibrium characterizations of Farrell (1987) and Rabin (1994). However, in our four-player setup, the nature of communication dynamics is not one of "all or nothing", in the sense that agreements are built gradually. Finally, the strong correlation between the frequency of convergence and the eventual coordination rate implies that the role of network structure in determining the efficiency of coordination outcome does depend on how well it facilitates the formation of implicit agreement among the players.

\subsection{Behavior in the Incomplete Networks}

Evidence in Section 4.1 shows that the distribution of coordinated actions in each of the three incomplete (star, kite, and line) networks turns out to be highly asymmetric in favor of the hub(s), but extra communication reduces such asymmetry. Also, given $T$, the degree of inequity is greater in the star network than in the kite network. We next explore the subjects' behavior in the incomplete networks. ${ }^{11}$ In our games with incomplete networks, there exist a number of equilibrium strategies that result in the hub obtaining disproportionately large payoffs. In order to facilitate the data analysis in the presence of multiple equilibria, we focus on identifying the most natural set of behaviors through which the hub captures his informational advantage: the hub insists on a single message/action throughout the entire game, while the other players follow the action of the hub's choice even after expressing different intentions of their own. ${ }^{12}$ This approach of isolating a particular behavioral pattern not only helps to

11. See Online Appendix III.2 for an analysis of behavior in the complete network.

12. It is straightforward to construct sequential equilibria of this kind under each incomplete network. For instance, in the star network, player $E$ 's insistence on, say, message $e$ is met with the belief by each 
TABLE 7. Behavior of the hub, and frequencies of nonswitching by the hub after initial disagreement.

\begin{tabular}{lcccc}
\hline Network & $T$ & Nonswitching & Switching & Nonswitching after initial disagreement \\
\hline Star & 2 & 0.90 & 0.10 & 0.81 \\
& & $(0.74)$ & $(0.78)$ & $(94)$ \\
& 5 & 0.79 & 0.21 & 0.78 \\
Kite & 2 & $(0.68)$ & $(0.50)$ & $(117)$ \\
& & 0.82 & 0.18 & 0.63 \\
& 5 & $(0.80)$ & $(0.83)$ & $(106)$ \\
& & 0.47 & 0.53 & $(157)$ \\
Line & 2 & $0.71)$ & $(0.74)$ & 0.57 \\
& & 0.71 & 0.29 & $(302)$ \\
& 5 & $(0.74)$ & $(0.82)$ & 0.37 \\
& & 0.48 & 0.52 & $(329)$ \\
\hline
\end{tabular}

organize a vast amount of data in our dynamic games where we need to consider history-dependent behaviors but turns out to explain many differences in outcomes across treatments.

Hub. Of particular interest is how often the hub insists on a single message/action throughout the entire game, which we refer to as nonswitching behavior; any other observed behavior is referred to as switching behavior. Table 7 presents the frequencies of nonswitching and switching behaviors in the incomplete networks, together with the frequency of the hub initially choosing his own favorite message conditional on each category (in parentheses).

The last column of Table 7 shows how reluctant the hub is to switch from his initial message when he finds himself in conflict with every other player in $t=1$, together with the number of observations (in parentheses).

This table reports a marked difference in the hub's behavior across the three incomplete networks. First, the hub in the star network exhibits a strong tendency to insist his initial message throughout the game (even after complete disagreement) both when $T=2$ and when $T=5$. None the less, such tendency is less pronounced when $T=5$ (0.79) compared to when $T=2(0.90)$. Second, the frequencies of nonswitching by each hub in the kite and line networks are lower compared to the star network; more importantly, these frequencies fall significantly as we increase $T$ (from 0.82 to 0.47 in kite and from 0.71 to 0.48 in line).

Next, Table 8 presents the distribution of coordinated actions in the underlying game, conditional on the hub's behavior.

Note here that, in both time treatments for the star network, coordination occurs mostly when the hub does not switch from his initial message: $0.96(=128 / 134)$ when $T=2$ and $0.84(=133 / 159)$ when $T=5$. A similar pattern is established

periphery that the others have also chosen the same message and will play action $e$ in the underlying game, while observation of any other message by $E$ triggers the (off-the-equilibrium) belief that someone has deviated, leading to coordination failure. 
TABLE 8. Frequencies of coordinated actions conditional on nonswitching/switching.

\begin{tabular}{llcccccc}
\hline Network & $T$ & Switching & $N$ & $E$ & $S$ & $W$ & Total \\
\hline Star & 2 & No & 15 & 87 & 12 & 14 & 128 \\
& & Yes & 2 & 1 & 0 & 3 & 6 \\
& 5 & No & 20 & 76 & 19 & 18 & 133 \\
\multirow{4}{*}{ Kite } & & Yes & 4 & 9 & 4 & 9 & 26 \\
& 2 & No & 12 & 74 & 9 & 5 & 100 \\
& & Yes & 10 & 0 & 7 & 7 & 24 \\
& 5 & No & 5 & 47 & 8 & 11 & 71 \\
\multirow{4}{*}{ Line } & 2 & Yes & 27 & 10 & 29 & 34 & 100 \\
& & No & 5 & 29 & 4 & 19 & 57 \\
& & Yes & 2 & 0 & 2 & 19 & 23 \\
& 5 & No & 8 & 29 & 8 & 12 & 57 \\
& & Yes & 20 & 14 & 16 & 18 & 78 \\
\hline
\end{tabular}

in the kite and line networks with $T=2: 0.81(=100 / 124)$ and $0.71(=57 / 80)$, respectively. However, in the kite and line networks with $T=5$, coordination is more likely to occur when the hub switches from his initial message: $0.58(=100 / 171)$ and $0.58(=78 / 135)$, respectively. Also, when coordination results from switching in these networks, the distribution of coordinated actions is not concentrated on the hubs' favorite actions. In particular, in the kite network with $T=5$, coordination is more likely to occur on actions other than the hub's favorite action $e$.

These findings are summarized as follows.

\section{RESULT 4.}

1. In the star network, the hub displays a strong tendency of nonswitching behavior both when $T=2$ and when $T=5$, although the frequency of switching behavior increases with T. Coordination occurs mostly under nonswitching.

2. In the kite and line networks, the hub displays a strong tendency of nonswitching behavior when $T=2$ but the frequency of switching behavior is greater than that of nonswitching when $T=5$. When coordination results from switching, the distribution of coordinated actions is not concentrated on the hubs' favorite actions.

The increased equity of coordinated outcomes in the incomplete networks under long communication therefore appears to result from the greater frequency of switching behavior from the hub(s). However, this behavioral shift as we move from $T=2$ to $T=5$ is substantially stronger in the kite and line networks than in the star network. ${ }^{13}$

13. Overall, individual-level behaviors across treatments appear consistent with the aggregate-level results. Table 5A in Online Appendix III.3 summarizes the individual-level frequencies of nonswitching behavior and choosing his own favorite message conditional on nonswitching behavior by the hub(s). 
TABLE 9. Behavior of the periphery: $m_{I}^{t}=m_{H}^{t-1}$.

\begin{tabular}{|c|c|c|c|c|c|c|c|}
\hline \multirow[b]{2}{*}{ Message in $t-1$} & \multirow[b]{2}{*}{ Network } & \multirow[b]{2}{*}{$T$} & \multicolumn{5}{|c|}{ Time $(t)$} \\
\hline & & & 2 & 3 & 4 & 5 & 6 \\
\hline \multirow{5}{*}{$m_{I}^{t-1} \neq m_{H}^{t-1}$} & \multirow[t]{2}{*}{ Star } & 2 & $0.42(528)$ & $0.66(318)$ & - & - & - \\
\hline & & 5 & $0.25(581)$ & 0.14 (475) & $0.16(422)$ & 0.38 (378) & $0.67(251)$ \\
\hline & \multirow[t]{2}{*}{ Kite } & 2 & $0.16(173)$ & 0.59 (149) & - & - & - \\
\hline & & 5 & $0.13(210)$ & $0.11(192)$ & 0.14 (177) & $0.41(145)$ & $0.68(104)$ \\
\hline & \multirow{2}{*}{ Line } & 2 & 0.27 (370) & $0.50(238)$ & - & - & - \\
\hline & & 5 & $0.22(421)$ & $0.23(342)$ & $0.33(281)$ & $0.50(201)$ & $0.66(138)$ \\
\hline \multirow{6}{*}{$m_{I}^{t-1}=m_{H}^{t-1}$} & \multirow[t]{2}{*}{ Star } & 2 & 0.97 (192) & $0.98(402)$ & - & - & - \\
\hline & & 5 & 0.97 (139) & $0.96(245)$ & 0.99 (298) & $0.99(342)$ & 0.99 (469) \\
\hline & \multirow[t]{2}{*}{ Kite } & 2 & $0.99(67)$ & $1.00(91)$ & - & - & - \\
\hline & & 5 & $0.84(50)$ & $0.93(68)$ & $0.98(83)$ & $0.96(115)$ & $0.96(156)$ \\
\hline & \multirow[t]{2}{*}{ Line } & 2 & 0.99 (110) & 0.99 (242) & - & - & - \\
\hline & & 5 & $0.95(59)$ & $0.96(138)$ & 1.00 (199) & $1.00(279)$ & $1.00(342)$ \\
\hline
\end{tabular}

Notes: A number in parentheses is the number of observations. $I$ is a periphery: $N / S / W$ in star, $W$ in kite, and $N / S$ in line. $H$ is the hub that $I$ is linked to: $E$ in star and kite, and $E / W$ in line. The message or action of periphery $I$ (hub $H$ ) in period $t$ is denoted by $m_{I}^{t}\left(m_{H}^{t}\right)$. The action stage is referred to as $t=T+1, T=2,5$.

Other Nodes. Given the different behavioral tendencies of the hub across treatments, it is important to understand how players in other nodes behave. In particular, we want to investigate why the hub's advantage is lower in the kite network than in the star network for each $T$. Because the only structural difference between the two networks is the additional link between players $N$ and $S$ in the kite network, the behavior of these players should hold key to answering this question. However, before addressing the behavior of these two players, we first consider how peripheries behave in the incomplete networks.

Table 9 presents the behavior of peripheries in the star, kite, and line networks. Because information about past play of the game flows to a periphery only through the hub that he is linked to, it is natural to examine a periphery's willingness to conform to the hub (i.e., choosing the hub's previous message). For this purpose, we divide the relevant histories of observations at the beginning of each period $t \leq T+1$ (including the action stage) into whether or not a periphery's message in the previous period coincided with the message chosen by the hub.

The following patterns are observed in all treatments. Not surprisingly, at a history in which the periphery and hub chose a common message in the previous period (the bottom panel of Table 9), the periphery continues to choose the same message almost surely. At other histories with disagreements, the periphery's tendency to copy the hub's previous message increases significantly towards the end of the entire game. Also, for a given network, this probability is higher at the end of the game when $T=5$ than when $T=2 .^{14}$

14. Table 6A in Online Appendix III.3 provides an individual-level analysis of peripheries' conformity at histories with disagreements. 
TABLE 10 . Behavior of players $N$ and $S$ in the kite network.

\begin{tabular}{|c|c|c|c|c|c|c|c|}
\hline \multicolumn{2}{|c|}{$(I \neq J=N$ or $S)$} & \multirow[b]{2}{*}{$T$} & \multicolumn{5}{|c|}{ Time $(t)$} \\
\hline Message in $(t-1)$ & Behavior in $t$ & & 2 & 3 & 4 & 5 & 6 \\
\hline \multirow{4}{*}{$m_{I}^{t-1}=m_{J}^{t-1} \neq m_{E}^{t-1}$} & \multirow[t]{2}{*}{$m_{I}^{t}=m_{I}^{t-1}$} & 2 & $0.95(60)$ & $0.56(50)$ & - & - & - \\
\hline & & 5 & $0.93(76)$ & $0.94(78)$ & $0.97(74)$ & $0.89(80)$ & $0.77(44)$ \\
\hline & \multirow[t]{2}{*}{$m_{I}^{t}=m_{E}^{t-1}$} & 2 & $0.05(60)$ & $0.44(50)$ & - & - & - \\
\hline & & 5 & $0.03(76)$ & $0.04(78)$ & $0.00(74)$ & $0.11(80)$ & $0.23(44)$ \\
\hline \multirow[t]{4}{*}{$m_{I}^{t-1} \neq m_{J}^{t-1} \neq m_{E}^{t-1}$} & \multirow[t]{2}{*}{$m_{I}^{t}=m_{I}^{t-1}$} & 2 & $0.67(236)$ & $0.40(98)$ & - & - & - \\
\hline & & 5 & $0.89(300)$ & $0.83(276)$ & $0.76(202)$ & $0.60(118)$ & $0.45(44)$ \\
\hline & \multirow{2}{*}{$m_{I}^{t}=m_{E}^{t-1}$} & 2 & $0.24(236)$ & $0.57(98)$ & - & - & - \\
\hline & & 5 & $0.04(300)$ & $0.09(276)$ & $0.10(202)$ & $0.30(118)$ & $0.50(44)$ \\
\hline \multirow[t]{4}{*}{$m_{I}^{t-1} \neq m_{J}^{t-1}=m_{E}^{t-1}$} & \multirow[t]{2}{*}{$m_{I}^{t}=m_{I}^{t-1}$} & 2 & $0.35(79)$ & $0.21(85)$ & - & - & - \\
\hline & & 5 & $0.62(61)$ & $0.77(43)$ & $0.62(61)$ & $0.55(60)$ & $0.20(74)$ \\
\hline & \multirow[t]{2}{*}{$m_{I}^{t}=m_{E}^{t-1}$} & 2 & $0.62(79)$ & $0.79(85)$ & - & - & - \\
\hline & & 5 & $0.34(61)$ & $0.21(43)$ & $0.36(61)$ & $0.43(60)$ & $0.77(74)$ \\
\hline
\end{tabular}

Notes: Player I's message or action in $t$ is denoted by $m_{I}^{t}$. A number in parentheses is the number of observations.

Let us now compare these observations with the behavior of $N$ and $S$ in the kite network. We examine the histories at which either of the two players is in disagreement with the hub, $E$. Because $N$ and $S$ can observe each other's past messages, the relevant histories at the beginning of $t \leq T+1$ are partitioned into the following three sets about the three players' messages in $t-1$ : (i) $N$ and $S$ played the same message different from $E$ 's message; (ii) all three players played distinct messages; (iii) either $N$ or $S$ played the same message as $E$. Table 10 presents the behavior of players $N$ and $S$ in the kite network at these histories.

The difference in behavior between these two players and a periphery is most clearly seen by the decisions made by $N$ and $S$ contingent on the first type of histories. Here, in both time treatments, the two players are much more likely to stick with their own previous message than to conform with the hub. In this case, the probability that either $N$ or $S$ switches to the hub's message when playing the underlying game is just 0.44 when $T=2$ and 0.23 when $T=5$. Even when all three players played differently, the probability of conformity is lower when $T=5$ (equal to 0.50 ), compared to the corresponding tendency exhibited by the periphery, $W$, in the same treatment (equal to 0.68 ), as seen in Table 9. However, when one of $N$ and $S$ has agreed with $E$ in the previous period, the other player is likely to conform to $E(0.79$ when $T=2$ and 0.77 when $T=5$ ). Together with the high tendency of conformity by the peripheries in the star and kite networks (Table 9), these observations (Table 10) lead to the following result.

RESUlt 5. Both when $T=2$ and when $T=5$, players $N$ and $S$ in the kite network are less likely to conform to the hub than the peripheries in the incomplete networks.

We have already seen that, when $T=2$, the hub in both star and kite networks exhibits nonswitching behavior (Result 4) and also such behavior is frequently 
accompanied by the hub's own favorite message/action (Table 7). Thus, Result 5 gives an explanation for why under this time treatment, the distribution of coordinated outcomes is less asymmetric in the kite network than in the star network. Furthermore, Result 5 suggests that the less conforming behavior of $N$ and $S$ is what induces the hub in the kite network to switch his messages much more frequently when $T=5$, which in turn reduces the hub's payoff advantage.

\section{Conclusion}

We have explored the role of network structure and length of pre-play communication in a symmetric four-player coordination game with conflicting preferences. Our main conclusions are that, in contrast to the multiple equilibrium predictions of standard theory, behavior and outcome depend more predictably on the network structure of preplay communication. Moreover, network structure has important implications for both issues of efficiency and equity of coordination. In particular, we have identified how certain network structures break the symmetry of players in the underlying game in such a way that confers strategic edge, and hence higher payoffs, to some individuals. None the less, the extent of such strategic advantage depends on the length of communication. When communication lasts longer, this advantage becomes weaker, which in turn makes coordination outcomes more equitable. Furthermore, our analysis demonstrates that such a positive time effect on equity is driven by greater information flows across individuals facilitated by the hub's switching behavior. In all treatments, coordination is mostly explained by convergence in communication, thereby suggesting that the players indeed announce their intended actions and negotiate over which outcome to coordinate on through the communication stage.

Our experimental findings suggest an important open question: does network structure matter when the players can engage in a very long cheap talk? ${ }^{15}$ Our experiments do show that the differences in the coordination rate and the distribution of coordinated actions become smaller across networks as the length of cheap talk is increased. However, we also observe that this effect is induced by particular behaviors. Although a fuller study to uncover the long-run implications of network structure lies beyond the scope of this paper, our findings suggest that such a study may need to address the precise channels of convergence in outcomes.

Although our study does not directly address the issue of optimal network/organization design, it uncovers potential variations in the performance of different networks when conflicting objectives are present. In our experiments, the complete network achieves the highest rate of coordination as well as the most symmetric distribution of outcomes. However, if we take into account the possible cost of each link and/or message, the issue of optimal communication network in

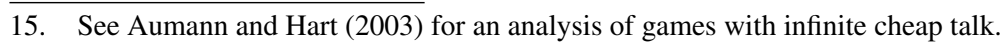


our setup remains open. ${ }^{16}$ For instance, the star network involves less communication and also appears to be effective in promoting common actions but at the expense of equitable payoffs. What do these observations imply for the merits of organizations and teams that have a leader endowed with superior access to information, relative to other more horizontal information-sharing arrangements? In order to address these questions, we would need a more detailed specification of how inequity aversion translates to inefficiencies elsewhere. Our analysis offers a framework that can be enriched to take on these interesting issues for future research.

\section{References}

Agell, Jonas and Per Lundborg (1999). "Theories of Pay and Unemployment: Survey Evidence from Swedish Manufacturing Firms." Scandinavian Journal of Economics, 97, 295-308.

Allen, Franklin and Douglas Gale (2000). "Financial Contagion." Journal of Political Economy, 108, $1-33$.

Alonso, Ricardo, Wouter Dessein, and Niko Matouschek (2008). "When Does Coordination Require Centralization?" American Economic Review, 98 (1), 145-179.

Angeletos, George-Marios and Jennifer La'O (2013). "Sentiments." Econometrica, 81, 739-779.

Aumann, Robert J. and Sergiu Hart (2003). "Long Cheap Talk.” Econometrica, 71, 1619-1660.

Bewley, Truman F. (1999). Why Rewards Don't Fall during a Recession. Harvard University Press.

Blinder, Alan S. and Don H. Choi (1990). "A Shred of Evidence on Theories of Reward Stickiness." Quarterly Journal of Economics, 105, 1003-1015.

Blume, Andreas and Andreas Ortmann (2007). "The Effects of Costless Pre-play Communication: Experimental Evidence from Games with Pareto-ranked Equilibria." Journal of Economic Theory, 132, 274-290.

Burton, Anthony, Graham Loomes, and Martin Sefton (2005). "Communication and Efficiency in Coordination Game Experiments." In Experimental and Behavioral Economics, Advances in Applied Microeconomics, Vol. 13, edited by John Morgan. JAI Press, pp. 63-85.

Calvó-Armengol, Antoni and Joan de Martí (2007). "Communication Networks: Knowledge and Decision.” American Economic Review, Papers and Proceedings, 97 (2), 86-91.

Calvó-Armengol, Antoni and Joan de Martí (2009). "Information Gathering in Organizations: Equilibrium, Welfare and Optimal Network Structure." Journal of the European Economic Association, 7, 116-161.

Camerer, Colin (2003). Behavioral Game Theory: Experiments in Strategic Interactions. Princeton University Press.

Campbell, Carl M. and Kunal Kamlani (1997). "The Reasons for Reward Rigidity: Evidence from a Survey of Firms." Quarterly Journal of Economics, 112, 759-789.

Chandler, Alfred D. (1962). Strategy and Structure: Chapters in the History of the American Industrial Enterprise. MIT Press.

Chwe, M. Suk-Young (2000). "Communication and Coordination in Social Networks." Review of Economic Studies, 67, 1-16.

Clark, Andrew E. and Andrew J. Oswald (1996). "Satisfaction and Comparison Income." Journal of Public Economics, 61, 359-381.

Cooper, Russell, Douglas V. DeJong, Robert Forsythe, and Thomas W. Ross (1989). "Communication in the Battle of the Sexes Game: Some Experimental Results." RAND Journal of Economics, $20,568-587$.

16. Early studies of organizations with explicit communication constraints include Marschak and Radner (1972). 
Cooper, Russell, Douglas V. DeJong, Robert Forsythe, and Thomas W. Ross (1992). "Communication in Coordination Games." Quarterly Journal of Economics, 107, 739-771.

Corbae, Dean and John Duffy (2008). "Experiments with Network Formation." Games and Economic Behavior, 64, 81-120.

Crawford, Vincent (1998). "A Survey of Experiments on Communication via Cheap Talk." Journal of Economic Theory, 78, 286-298.

Crawford, Vincent and Joel Sobel (1982). "Strategic Information Transmission." Econometrica, 50, 579-594.

Diamond, Douglas W. and Philip H. Dybvig (1983). "Bank Runs, Deposit Insurance, and Liquidity." Journal of Political Economy, 91, 401-419.

Duffy, John and Nick Feltovich (2002). "Do Actions Speak Louder than Works? An Experimental Comparison of Observation and Cheap Talk." Games and Economic Behavior, 39, 1-27.

Farrell, Joseph (1987). "Cheap Talk, Coordination and Entry." RAND Journal of Economics, 18, 34-39.

Fischbacher, Urs (2007). "z-Tree: Zurich Toolbox for Ready-made Economic Experiments." Experimental Economics, 10, 171-178.

Galeotti, Andrea, Christian Ghiglino, and Francesco Squintani (2013). "Strategic Information Transmission in Networks." Journal of Economic Theory, 148, 1751-1769.

Goyal, Sanjeev (2007). Connections: An Introduction to the Economics of Networks. Princeton University Press.

Hagenbach, Jean and Frédéric Koessler (2009). "Strategic Communication Networks." Review of Economic Studies, 77, 1072-1099.

Hart, Oliver and Bengt Holmström (2010). “A Theory of Firm Scope.” Quarterly Journal of Economics, 125, 483-513.

Hart, Oliver and John Moore (2005). "On the Design of Hierarchies: Coordination versus Specialization." Journal of Political Economy, 113, 675-702.

Jackson, Matthew O. (2008). Social and Economic Networks. Princeton University Press.

Kearns, Michael, Stephen Judd, Jinsong Tan, and Jennifer Wortman (2009). "Behavioral Experiments on Biased Voting in Networks." Proceedings of the National Academy of Sciences, 106, 1347 1352.

Marschak, Jacob and Roy Radner (1972). Economic Theory of Teams. Yale University Press.

Milgrom, Paul and John Roberts (1992). Economics, Organization and Management. Prentice-Hall, NJ.

Morris, Stephen and Hyun Song Shin (1998). "Unique Equilibrium in a Model of Self-Fulfilling Currency Attacks." American Economic Review, 88 (3), 587-597.

Ochs, Jack (2008). "Coordination Problems and Communication.” In The New Palgrave Dictionary of Economics (2nd Edition), edited by Stephen N. Durlauf and Lawrence E. Blume. Palgrave Macmillan.

Rabin, Matthew (1994). “A Model of Pre-Game Communication.” Journal of Economic Theory, 63, 370-391.

Sloan, Alfred P. (1990). My Years with General Motors. Doubleday, New York.

Wasserman, Stanley and Katherine Faust (1994). Social Network Analysis: Methods and Applications. Cambridge University Press.

\section{Supporting Information}

Additional Supporting Information may be found in the online version of this article at the publisher's website:

Online Appendix 